\title{
Developmental Regulation of the Rabbit Blood-Brain Barrier LAT1 Large Neutral Amino Acid Transporter mRNA and Protein
}

\author{
RUBEN J. BOADO, JIAN YI LI, AND WILLIAM M. PARDRIDGE \\ Department of Medicine, University of California at Los Angeles, Los Angeles, California 90024, U.S.A.
}

\section{ABSTRACT}

\begin{abstract}
The expression of the blood-brain barrier (BBB) LAT1 large neutral amino acid transporter mRNA and protein was investigated in development in rabbits. The BBB LAT1 mRNA was down-regulated with postnatal development. However, the BBB immunoreactive LAT1 protein was unchanged in postnatal development, despite an up-regulation of the BBB GLUT1 glucose transporter protein during this period. The dissociation between LAT1 protein and mRNA levels in development is consistent with posttranscriptional regulation of BBB LAT1 gene expression. (Pediatr Res 55: 557-560, 2004)
\end{abstract}

BBB, blood-brain barrier

BCM, brain cell membrane

GLUT1, glucose transporter type 1

LAT1, large neutral amino acid transporter type 1

4F2hc, heavy chain subunit of the LAT1 heterodimer
The transport of the large neutral amino acids from blood to brain is mediated by the LAT1 large amino acid transporter located at the brain capillary endothelial membrane $(1,2)$, which forms the BBB in vivo. The LAT1 is also called the leucine-preferring or L-system amino acid transporter (3), and was originally cloned from C6 glial cells (4). The pools of amino acids in blood and in the brain intracellular spaces are separated by two membranes in series: the BBB and the BCM. Owing to the vastly greater surface area of the $\mathrm{BCM}$ compared with the BBB (5), the rate-limiting step in brain uptake of circulating amino acids is BBB transport (6). Therefore, amino acid availability in brain is regulated by $\mathrm{BBB}$ transport, and the availability of large neutral amino acids in brain regulates brain metabolism. For example, the influx of amino acids from blood to brain approximates the rates of amino acid incorporation into brain proteins (6). Under normal physiologic conditions, the synthesis of brain proteins is not influenced by the availability of amino acids (7). However, this pathway is inhibited when the supply of brain amino acids is altered by a singular hyperaminoacidemia, like phenylketonuria (PKU) (8-11). PKU causes a decrease in amino acid supply in brain by competition effects at the $\mathrm{BBB}$, and this decrease in brain protein synthesis is normalized by the administration of amino

Received July 18, 2003; accepted November 20, 2003

Correspondence: Ruben J. Boado, Ph.D., Department of Medicine, UCLA Warren Hall

13-164, 900 Veteran Ave., Los Angeles, CA 90024, U.S.A.; e-mail: rboado@mednet.ucla.edu Supported by Grant NS-40016 from the National Institutes of Health.

DOI: 10.1203/01.PDR.0000113461.07950.72 acids (12). In addition, many pathways of brain neurotransmitter synthesis are also rate-affected by the cerebral availability of precursor large neutral amino acids (6). In the developing brain, there are changes in protein synthesis that parallel the general reduction in cellular density of the older brain compared with the fetal or neonatal brain $(13,14)$. Whether there is a parallel down-regulation of the BBB LAT1 gene expression with development is not known, although other BBB-nutrient transporters are developmentally regulated. For example, the gene expression of the BBB GLUT1 glucose transporter mRNA is up-regulated as suckling animals are weaned $(15,16)$. However, the regulation of the GLUT1 protein at the BBB is not linked to that of the BBB GLUT1 mRNA in developing rabbits, consistent with a posttranscriptional mechanism of regulation of BBB GLUT1 gene expression (16). The BBB GLUT1 glucose transporter protein is initially down-regulated after birth (16), when suckling animals use ketone bodies as a principal carbon source for the brain (15). Later in postnatal development, the BBB GLUT1 transporter protein is up-regulated as the brain switches from ketone body fuels to carbohydrate $(15,16)$. The hypothesis that BBB LAT1 gene expression is developmentally regulated was examined in the present study, which investigates the abundance of the BBB LAT1 mRNA and protein in newborn, 21-d suckling, and adult rabbits.

\section{MATERIALS AND METHODS}

Isolation of poly $A+R N A$ and Northern blot analyses. The LAT1 is a heterodimer comprised of a light chain encoded by 
the LAT1 cDNA and a heavy chain encoded by the $4 \mathrm{~F} 2 \mathrm{hc}$ cDNA (4). The $4 \mathrm{~F} 2 \mathrm{hc}$ subunit, also designated CD98, is an $80-\mathrm{kD}$ glycoprotein with a single transmembrane region and is a member of the type 2 membrane protein family, which is ubiquitous in cells (17). Therefore, the mRNA levels for both LAT1 and 4F2he subunits of the LAT1 heterodimer were investigated in the present study. The abundance of the BBB LAT1 mRNA was determined by Northern blot analysis of poly A+ RNA purified from freshly isolated capillaries obtained from the brains of newborn (i.e. $1 \mathrm{~d}$ old), young (i.e. $21 \mathrm{~d}$ old), and adult New Zealand rabbits. All experimental protocols were reviewed and approved by the Institutional Animal Research Committee. Brain capillaries were isolated by mechanical homogenization from 24 newborn, 15 young, or 5 adult rabbits as previously described (1). Brain capillaries were free of adjoining brain tissue, and poly A+ RNA was isolated using a single-step method previously reported (18). The yields of poly A+ RNA were 5.2, 14.4, and $4.1 \mu \mathrm{g}$ for newborn, young, and adult rabbits, respectively, and the $\mathrm{OD}_{260 / 280}$ was $>1.8$ for all samples. Two micrograms of poly A+ RNA aliquots were resolved in 1.5\% agarose-2.2 $\mathrm{M}$ formaldehyde gels and then blotted onto GeneScreen Plus membranes (PerkinElmer Life Science, Boston, MA, U.S.A.) (18). Northern blots were probed with ${ }^{32} \mathrm{P}$-labeled rabbit LAT1, 4F2hc, $\beta$-actin cDNA, or oligo $\mathrm{d}(\mathrm{T})_{18}$, as described previously $(1,18)$.

Western blot analyses. The levels of the immunoreactive LAT1 and GLUT1 transporter proteins in developing rabbit brain capillaries were determined by Western blot analysis. Brain capillaries were prepared from newborn, young, and adults rabbits, and solubilized in SDS buffer $(0.05 \mathrm{M}$ Tris- $\mathrm{HCl}$ $\mathrm{pH}=7.5,2 \% \mathrm{SDS})$ in an end-over-end mixer at $4^{\circ} \mathrm{C}$ for $16 \mathrm{~h}$. The concentration of proteins was determined using the BCA protein assay kit (Pierce Chemical, Rockford, IL, U.S.A.). Aliquots of $20 \mu \mathrm{g}$ protein were resolved in $12 \%$ SDS-PAGE under reducing conditions ( $5 \%$ 2-mercaptoethanol) and electroblotted onto $0.45 \mu$ nitrocellulose membranes (Bio-Rad, Hercules, CA, U.S.A.). Immunoblot analyses were performed with polyclonal antibodies directed to the LAT1 or GLUT1 peptides as previously described (19). The chicken anti-LAT1 polyconal antibody directed to the amino terminus of rat LAT1 was kindly provided by Dr. Lester Drewes (University of Minnesota, Minneapolis, MN, U.S.A.) (2). This antibody cross-reacts with the rabbit LAT1 amino terminus as the immunoreactivity was completely blocked by absorption of the antiserum with the synthetic peptide encoding the rat LAT1 amino terminus used for the production of the antibody (data not shown). This is consistent with conservation of amino acid sequence at the amino terminus of rat (4) and rabbit LAT1 (20). The secondary antibody used for LAT1 Western blot was a rabbit anti-chicken $\operatorname{IgY}$ conjugated to horseradish peroxidase (Vector Laboratories, Burlingame, CA, U.S.A.). Membranes were also probed with the anti-GLUT1 antibody as previously described (19), followed by biotinylated goat anti-rabbit $\mathrm{IgG}$ $(\mathrm{H}+\mathrm{L})$ and Vectastain $\mathrm{ABC}$ peroxidase kit (Vector Laboratories). Membranes were blocked with SEA BLOCK blocking buffer (Pierce Chemical). Immunoreactive bands were visualized with ECL western blot analysis system and Hyper film (Amersham Pharmacia Biotech, Piscataway, NJ, U.S.A.).

\section{RESULTS}

The abundance of the BBB LAT1 transcript was inversely correlated with age (Fig. 1). There was a down-regulation in the abundance of the BBB LAT1 mRNA in adult and 3-wk-old rabbits compared with newborn animals. Similar downregulation was observed in the $4 \mathrm{~F} 2 \mathrm{hc}$ mRNA and in the actin transcript (Fig. 1). Postnatal down-regulation of BBB mRNA
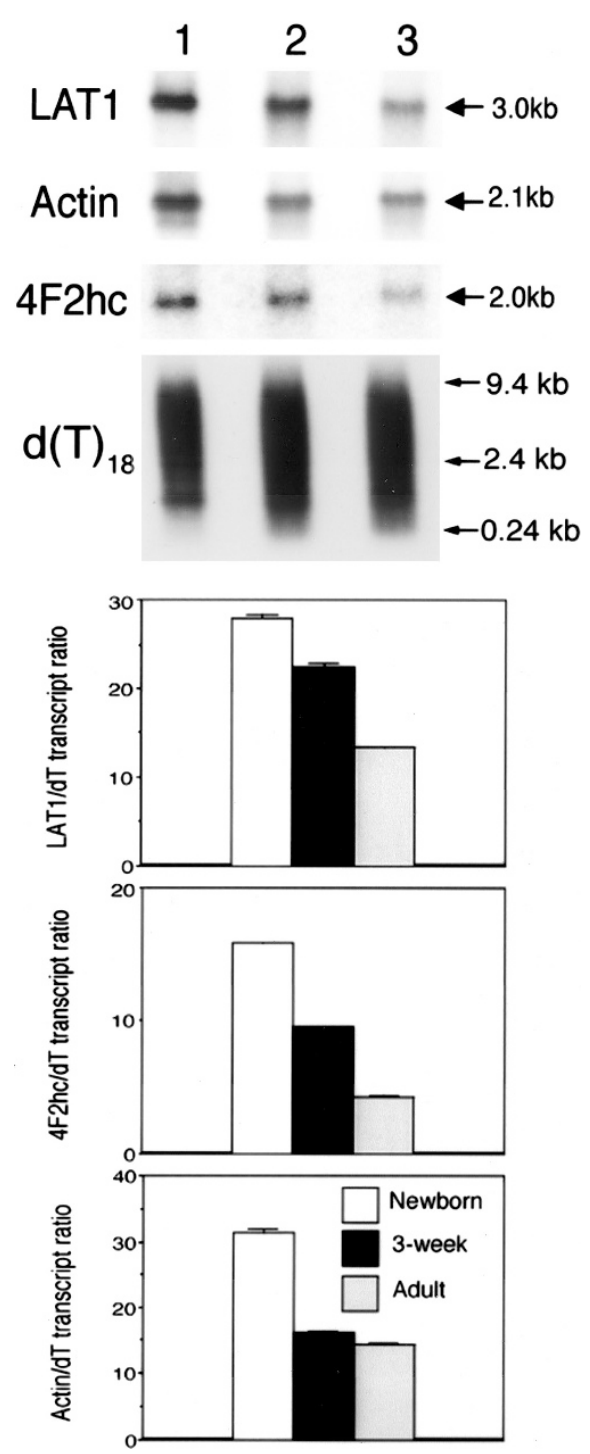

Figure 1. (Top) Northern blotting of rabbit brain microvascular mRNA. Two micrograms of poly A+ RNA isolated from brain capillaries of newborn (lane 1), 21-d-old (lane 2), and adult rabbits (lane 3) were resolved in agaroseformaldehyde gels. Northern blots were successively probed with ${ }^{32} \mathrm{P}$-labeled rabbit LAT1, rat 4F2hc, and mouse $\beta$-actin cDNA, respectively. Blots were also hybridized with a ${ }^{32} \mathrm{P}$-labeled oligo $\mathrm{d}(\mathrm{T})_{18}$ probe to allow for standardization of RNA applied per lane. Autoradiograms were exposed to Kodak Biomax MS film with intensifying screens as follows: LAT1, $90 \mathrm{~min}$ at $-70^{\circ} \mathrm{C}$; actin, $240 \mathrm{~min}$ at $-70^{\circ} \mathrm{C} ; 4 \mathrm{~F} 2 \mathrm{hc}, 6 \mathrm{~d}$ at $-70^{\circ} \mathrm{C}$; and $\mathrm{d}(\mathrm{T})_{18}, 90 \mathrm{~min}$ at $22^{\circ} \mathrm{C}$. X-ray films were scanned with a Umax PowerLook III scanner and transferred to Adobe Photoshop 5.5 on a G4 Power Macintosh. The size of the transcript is indicated on the right-hand side of the figure. (Bottom) Data were normalized by determination of the ratio of hybridization density for the mRNA of interest divided by the same for the $\mathrm{d}(\mathrm{T})_{18}$. There is a reduction in the levels of LAT1, 4F2hc, and actin in 21-d-old and adult rabbits compared with newborn animals. 
encoding for cytoskeletal proteins such as actin or tubulin has been reported previously (16), and this down-regulation is mediated by posttranscriptional mechanisms (21). Because similar down-regulation of gene expression was seen in all three investigated transcripts, the Northern results were normalized by hybridization with ${ }^{32} \mathrm{P}$-labeled oligo $\mathrm{d}(\mathrm{T})_{18}$ probe (Fig. 1), and the data expressed as mRNA of interest/dT transcript ratio (Fig. 1, bottom). The ${ }^{32} \mathrm{P}-\mathrm{d}(\mathrm{T}){ }_{18}$ probe hybridized with a variety of polyadenylated mRNA ranging from 9 to $0.2 \mathrm{~kb}$, and no significant changes in the hybridization signal was seen among samples (Fig. 1), indicating the differences in mRNA with age did not reflect a generalized decrease in mRNA levels.

The LAT1 light chain forms a heterodimer with the glycosylated 4F2he heavy chain (4), and insertion of the LAT1 subunit within the membrane requires association with the 4F2he subunit (22). Both LAT1 and 4F2he mRNA are upregulated in newborn rabbits compared with young and adults animals (Fig. 1). However, based on the time required to develop the Northern blot of the LAT1 and 4F2hc transcripts, the LAT1 mRNA is more abundant than the 4F2hc mRNA, which has a relative abundance comparable to the actin mRNA (Fig. 1).

In contrast to the down-regulation with development of the LAT1 mRNA (Fig. 1), there was no significant change in the levels of the immunoreactive LAT1 protein in developing rabbit brain capillaries (Fig. 2). The constancy of the BBB LAT1 protein at the BBB of developing rabbit brain contrasts with the up-regulation of the BBB GLUT1 glucose transporter (Fig. 2).

\section{DISCUSSION}

The results of this study are consistent with the following conclusions. First, there is a divergence in the regulation of the BBB LAT1 mRNA and protein in developing rabbits, such that the level of the LAT1 protein at the BBB is maintained constant, despite a postnatal down-regulation of the BBB LAT1 mRNA (Figs. 1 and 2). Second, there is a divergence in the regulation of the BBB GLUT1 and LAT1 transporter proteins, because the former is up-regulated with development and the latter is maintained constant during development in rabbits (Fig. 2).

The up-regulation of the BBB GLUT1 protein with postnatal development is expected and parallels the switch from ketone body fuels to carbohydrate fuels that occurs when suckling animals are weaned with development (15). The constancy of the BBB LAT1 amino acid transporter protein in the developing rabbit contrasts with the regulation of the GLUT1 glucose transporter (Fig. 2) and suggests that the brain maintains a relatively constant rate of amino acid transport across the BBB in development. The brain may maintain a relatively constant level of BBB LAT1 to offset sudden decreases in plasma amino acid levels, owing to variations in dietary protein intake. The brain weight is decreased in animals subjected to intrauterine growth retardation (23). The rates of amino acid influx from blood to brain across the BBB approximate the rates of amino acid incorporation into brain proteins (6). Therefore, a diet-
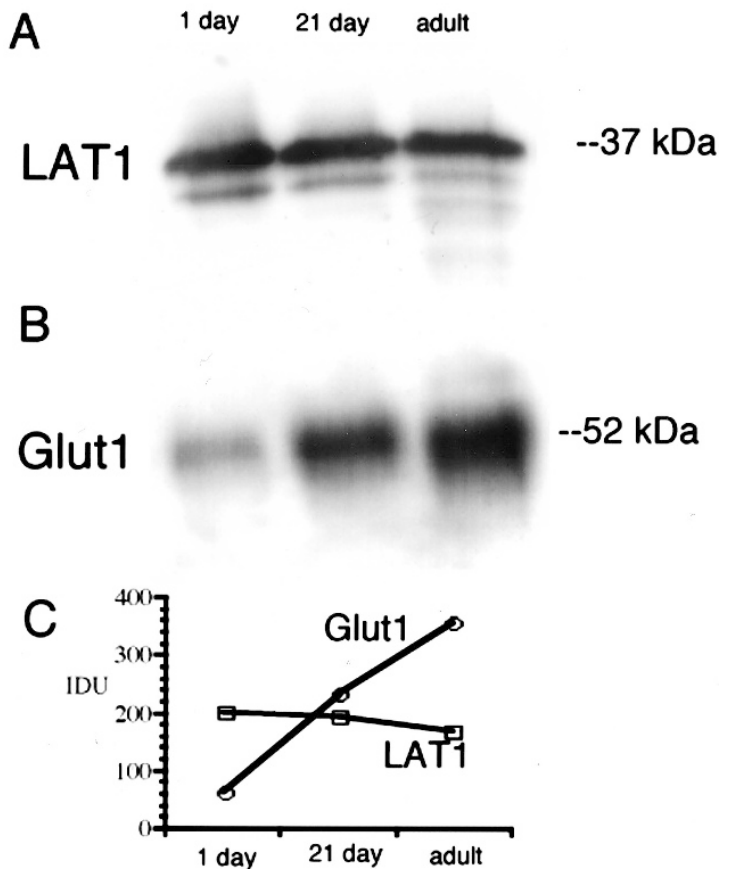

Figure 2. Western blotting of rabbit brain microvascular proteins. Twenty micrograms protein isolated from brain capillaries of newborn, 21-d-old, and adult rabbits were resolved in $12 \%$ SDS-PAGE gels and electroblotted onto $0.45 \mu$ nitrocellulose membranes. (A) Immunoblot probed with a chicken anti-LAT1 polyclonal antibody directed to the amino terminus of LAT1. $(B)$ Membrane probed with the anti-GLUT1 antibody. Immunoreactive bands were visualized with ECL Western blot analysis system and x-ray films were scanned as described in Figure 1. The integrated density units (IDU) corresponding to the bands shown in $A$ and $B$ were obtained with the National Institutes of Health Image program and are depicted in panel $C$. The molecular weight of the immunoreactive bands is indicated on the right-hand side of the figure in panels $A$ and $B$. No significant changes were observed in the levels of the LAT1 protein among newborn, 21-d-old, and adult rabbits. In contrast, the BBB GLUT1 glucose transporter protein was up-regulated in the 21-d-old, and adult rabbits compared with the newborn animals.

induced decrease in plasma amino acids could adversely affect brain protein synthesis. One mechanism to protect the brain against amino acid deprivation is to maintain a relatively high level of BBB LAT1 protein expression.

The preservation of the BBB LAT1 transporter protein with development occurs in parallel with a down-regulation in the abundance of the LAT1 mRNA in 3-wk-old and adult animals compared with newborn rabbits (Fig. 1). This divergence in the levels of the mRNA and the protein for LAT1 may result from a posttranscriptional mechanism of BBB LAT1 gene expression, whereby the translational efficiency for the LAT1 mRNA increases with development. Evidence for a related mechanism of posttranscriptional regulation of LAT1 gene expression was obtained in a study of the regulation of BBB LAT1 gene expression in hypoxia (24). The decrease in BBB LAT1 mRNA induced by hypoxia was associated with a destabilization of the LAT1 mRNA (24). Posttranscriptional mechanisms of regulation of the BBB LAT1 may also be involved in development wherein increased stabilization of the BBB LAT1 mRNA may result in augmented abundance of this transcript in newborn animals (Fig. 1).

Posttranscriptional regulation of BBB LAT1 gene expression would require the interaction between cellular RNA bind- 
ing proteins and the LAT1 mRNA. A similar mechanism occurs for the GLUT1 glucose transporter mRNA. The GLUT1 mRNA 3'-untranslated region (UTR) interacts with an $80-\mathrm{kD}$ cytosolic trans-acting protein that leads to mRNA stabilization in ischemia or glucose deprivation (25-27). In addition, a $40-\mathrm{kD}$ polysome regulatory protein is associated with GLUT1 mRNA degradation via endonuclease action in brain tumors (28). The LAT1 mRNA also binds to several polysome proteins at the brain endothelium, including 40-, 70-, and $80-\mathrm{kD}$ proteins that are exclusively expressed in the polysome fraction of brain endothelial cells (24). The interaction of polysome proteins with the LAT1 mRNA may contribute to posttranscriptional regulation of BBB LAT1 gene expression in development.

\section{CONCLUSION}

In summary, the present study demonstrates that the BBB LAT1 mRNA and protein are divergently regulated in development, which is consistent with a posttranscriptional mechanism of regulation of BBB LAT1 gene expression in development. The stable level of BBB LAT1 transporter protein, despite the developmental down-regulation of the BBB LAT1 mRNA, may serve to maintain the constancy of amino acid availability within the developing brain. Such an adaptive mechanism would insure that amino acid availability is not rate-limiting for postnatal cerebral protein synthesis. It is possible that a similar adaptive response occurs in other physiologic states, such as fasting or malnutrition. An up-regulation of the BBB LAT1 transporter, in parallel with a sustained depletion in plasma amino acid availability, would serve to selectively maintain the supply of essential amino acids within the brain.

\section{REFERENCES}

1. Boado RJ, Li JY, Nagaya M, Zhang C, Pardridge WM 1999 Selective expression of the large neutral amino acid transporter at the blood-brain barrier. Proc Natl Acad Sci U S A 96:12079-12084

2. Duelli R, Enerson BE, Gerhart DZ, Drewes LR 2000 Expression of large amino acid transporter LAT1 in rat brain endothelium. J Cereb Blood Flow Metab 20:1557-1562

3. Christensen HN 1969 Some special kinetic problems of transport. Adv Enzymol Relat Areas Mol Biol 32:1-20

4. Kanai Y, Segawa H, Miyamoto K, Uchino H, Takeda E, Endou H 1998 Expression cloning and characterization of a transporter for large neutral amino acids activated by the heavy chain of 4F2 antigen (CD98). J Biol Chem 273:23629-23632

5. Lund-Andersen H 1979 Transport of glucose from blood to brain. Physiol Rev 59:305-352
6. Pardridge WM 1983 Brain metabolism: a perspective from the blood-brain barrier Physiol Rev 63:1481-1535

7. Wurtman RJ, Moskowitz MA, Munro HN 1979 Transsynaptic control of neuronal protein synthesis. In: Schmitt FO, Norden FG (eds) The Neurosciences: Fourth Study Program. MIT Press, Cambridge, MA, pp 897-909

8. Hughes JV, Johnson TC 1977 The effects of hyperphenylalaninaemia on the concentrations of aminoacyl-transfer ribonucleic acid in vivo. Biochem J 162:527-537

9. Koch R, Moats R, Guttler F, Guldberg P, Nelson M 2000 Blood-brain phenylalanine relationships in persons with phenylketonuria. Pediatrics 106:1093-1096

10. Moller HE, Weglage J, Wiedermann D, Ullrich K 1998 Blood-brain barrier phenylalanine transport and individual vulnerability in phenylketonuria. J Cereb Blood Flow Metab 18:1184-1191

11. Shulkin BL, Betz AL, Koeppe RA, Agranoff BW 1995 Inhibition of neutral amino acid transport across the human blood-brain barrier by phenylalanine. J Neurochem 64:1252-1257

12. Binek-Singer P, Johnson TC 2061982 The effects of chronic hyperphenylalaninaemia on mouse brain protein synthesis can be prevented by other amino acids. Biochem $\mathrm{J}$ 407-414

13. Dunlop DS, van Elden W, Lajtha A 1974 A method for measuring brain protein synthesis rates in young and adult rats. J Neurochem 22:337-344

14. Goldspink DF 1988 Protein turnover and growth of the rat brain from the foetus to old age. J Neurochem 50:1364-1368

15. Cremer JE, Cunningham VJ, Pardridge WM, Braun LD, Oldendorf WH 1979 Kinetics of blood-brain barrier transport of pyruvate, lactate, and glucose in suckling, weaning, and adult rats. J Neurochem 33:439-445

16. Dwyer KJ, Pardridge WM 1993 Developmental modulation of blood-brain barrier and choroid plexus GLUT1 glucose transporter mRNA and immunoreactive protein in rabbits. Endocrinology 132:558-565

17. Wells RG, Lee W-S, Kanai Y, Leiden JM, Hedieger MA 1992 The 4F2 antigen heavy chain induces uptake of neutral and dibasic amino acids in Xenopus oocytes. J Biol Chem 267:15285-15288

18. Boado RJ, Pardridge WM 1991 A one-step procedure for isolation of poly A+ mRNA from isolated brain capillaries and endothelial cells in culture. J Neurochem 57:2136-2139

19. Pardridge WM, Boado RJ, Farrell CR 1990 Brain-type glucose transporter (GLUT1) is selectively localized to the blood-brain barrier. Studies with quantitative Western blotting and in situ hybridization. J Biol Chem 265:18035-18040

20. Boado RJ, Li JY, Pardridge WM 2003 Site-directed mutagenesis of rabbit LAT1 at amino acids 219 and 234. J Neurochem 84:1322-1331

21. Bond JF, Farmer SR 1983 Regulation of tubulin and actin mRNA production in rat brain: expression of a new $\beta$-tubulin mRNA with development. Mol Cell Biol 3:1333-1342

22. Nakamura E, Sato M, Yang H, Miyagawa F, Harasaki M, Tomita K, Matsuoko S, Noma A, Iwai K, Minato N 1999 4F2 (CD98) heavy chain is associated covalently with an amino acid transporter and controls intracellular trafficking and membrane topology of 4F2 heterodimer. J Biol Chem 274:3009-3016

23. Harel S, Yavin E, Tomer A, Barak Y, Binderman I 1985 Brain: body ratio and conceptional age in vascular-induced intrauterine growth retarded rabbits. Brain Dev 7:575-579

24. Boado RJ, Li JY, Pardridge WM 2003 Hypoxia induces de-stabilization of the LAT1 large neutral amino acid transporter mRNA in brain capillary endothelial cells. J Neurochem 85:1037-1042

25. Boado RJ, Pardridge WM 1993 Glucose deprivation causes post-transcriptional enhancement of brain capillary endothelial glucose transporter gene expression via GLUT1 mRNA stabilization. J Neurochem 60:2290-2296

26. Boado RJ, Pardridge WM 2002 Glucose deprivation and hypoxia increase the expression of the GLUT1 glucose transporter via a specific mRNA cis-acting regulatory element. J Neurochem 80:552-554

27. Tsukamoto H, Hamada Y, Wu D, Boado RJ, Pardridge WM 1998 GLUT1 glucose transporter: differential gene transcription and mRNA binding to cytosolic and polysome proteins in brain and peripheral tissues. Brain Res Mol Brain Res 15:170177

28. Tsukamoto H, Boado RJ, Pardridge WM 1996 Differential expression in glioblastoma multiforme and cerebral hemangioblastoma of cytoplasmic proteins that bind two different domains within the 3'-untranslated regions of the human glucose transporter 1 (GLUT1) messenger RNA. J Clin Invest 97:2823-2832 